\title{
POWER-GENERATING FUEL BASED ON THE PROCESSING OF MUNICIPAL SOLID WASTE ORGANIC COMPONENTS
}

\author{
Temirbekova M.N. ${ }^{1}$, Wójcik W. ${ }^{2}$ \\ ${ }^{1}$ Almaty University of Power Engineering and Telecommunications named after Gumarbek Daukeev, \\ Almaty, Kazakhstan, m.temirbekova@aues.kz \\ ${ }^{2}$ Lublin University of Technology, Lublin, Poland
}

\begin{abstract}
The article considers effective technologies for processing the organic fraction of solid waste, involving the use of various approaches with the concept of preserving the ecology of the environment. Biomass cannot be simply collected and burned, the authors suggest using an effective method of its processing, which will allow fuel from it. To obtain energy, biomass can be used to produce biogas or liquid biofuels using various technological processes, for example, by fermentation. They, in turn, can be converted into electricity and heat, through combustion or the creation of fuel cells or used as fuel for motor vehicles. The purpose of this article is to use alternative methods, such as pretreatment of the organic fraction of municipal solid waste, ethanol fermentation with alcohol yeast, and anaerobic digestion are attracting increased attention. Using these methods, a liquid with alcohol-containing substances has been obtained from $1.5 \mathrm{~kg}$ of the organic fraction of municipal solid waste, in which the percentage of ethyl alcohol was $97.5 \%$. Therefore, organic municipal solid waste can be a promising source of fuel in modern energy.
\end{abstract}

Keywords: organic fraction of municipal solid waste, bioethanol, fermentation, ethanol fermentation with alcohol yeast, renewable energy sources.

\section{Introduction}

Nowadays, the production of ethanol from abundant and cheap waste, for example, agricultural waste [1-3], solid municipal and food waste [4-5] are of great interest. Among these inexpensive substrates organic solid municipal waste is an abundant raw material with zero cost and due to the excessive urban concentration and the emergence of large megapolises, the waste situation is deteriorating. Today, about $70 \%$ of municipal solid waste still come to landfills or uncontrolled disposal sites, which often pollute surface water, underground water or soil and emit greenhouse gases. Among the methods of municipal solid waste disposal in the world practice, the waste landfilling has gained the most practical widespread, but judging by the experience of waste management of the world's major economies, this type of disposal at the present time is becoming unpromising and makes no economic sense [6].

It should be noted that the composition and morphology of organic municipal solid waste are influenced by various factors, including culture, location, environmental conditions and climate, as well as the level of economy and development of this society [7]. Every year, municipal solid waste generated in emerging countries contains $40-88 \%$ of food waste [8-10]. The organic fraction of waste consists of starch, lignocellulose and lipids. Starch and lignocelluloses have great potential to be converted to ethanol, while other lipids cannot be converted to ethanol without pretreatment, but these biodegradable components can be converted to biogas by anaerobic digestion. Pretreatment involves increasing the bioavailability of lignocellulose, using the cellulase enzyme. Hydrothermal pretreatment reduces the formation of fermentation inhibitors that result from the breakdown and degradation of sugar. Pretreatment is an environmentally friendly process, since no chemicals are used, this treatment reduces the formation of hemicellulose and improves the availability of the enzyme for cellulose [11-12].

\section{Materials and methods}

For this qualitative experiment, fractional models of organic components of municipal solid waste have been used, which were formed in accordance with a similar chemical composition of waste, as well as a sample with real organic components from the solid municipal waste landfill of Tartyp Joint Stock Company 
in Almaty, that is, the very same organic which is formed every day. A total of 6 fractions were collected with different chemical compositions and weights.

- natural sample from the municipal solid waste landfill in Almaty (1500 g);

- model fraction with lipids (509 g);

- model fraction with cellulose $(850 \mathrm{~g})$;

- model fraction with carbohydrates $(900 \mathrm{~g})$;

- model fraction with fructose $(1164 \mathrm{~g})$

- combined fraction (cellulose $-850 \mathrm{~g}$, carbohydrates $-900 \mathrm{~g}$, lipids $-509 \mathrm{~g}$, fructose $-1164 \mathrm{~g}$ ).

A qualitative experiment includes the following main stages: preliminary hydrothermal treatment, enzymatic hydrolysis (by such enzymes as: amylase, glucavamarine, amilosubtiline, cellulose), ethanol fermentation (using alcohol yeast) of the liquid fraction of waste. Each sample is formed in accordance with the composition, the selection of samples is based on what elements are usually present in the waste, humidity and $\mathrm{pH}$ are determined, after which hydrothermal treatment is carried out at $120^{\circ} \mathrm{C}$ for 4 hours. After the end of hydration, qualitative reactions are carried out for the presence of starch using iodine and glucose, then the samples are separated into liquid and solid fractions and the fermentation process is started. It is necessary to add $1.5 \mathrm{~g}$ of amylosubtilin in the liquid part of each sample for 1.5 hours at $65^{\circ} \mathrm{C}$, the next stage is the addition of $2 \mathrm{~g}$ of glucavamarine for 1.5 hours at $50^{\circ} \mathrm{C}$. Then $2 \mathrm{~g}$ of cellulase is added to the solid part of fractional models for 1.5 hours at $50^{\circ} \mathrm{C}$ and also $1.5 \mathrm{~g}$ of amylase at $650^{\circ} \mathrm{C}$ for 1.5 hours. After the fermentation process is completed, ethanol fermentation is carried out, during which the alcohol yeast (15 $\mathrm{g}$ ) is added to the liquid part in order to produce ethanol [13].

\section{Research results}

As a result of a qualitative experiment, liquids with different volumes have been obtained from each model sample after preliminary hydrothermal treatment, fermentation, and ethanol fermentation, which have been then analyzed for the presence of alcohol-containing substances. Different masses of samples were taken and, accordingly, different volumes of substances were obtained, since it was important for our experiment to identify the presence of ethanol and its concentration in the samples.

Table1. Results of ethanol fermentation with alcohol yeast

\begin{tabular}{|l|l|c|}
\hline & Sample name and weight $(\mathrm{g})$ & $\begin{array}{l}\text { Amount of liquid after ethanol } \\
\text { fermentation with alcohol yeast }(\mathrm{ml})\end{array}$ \\
\hline 1. & Natural sample from the solid waste landfill in Almaty $(1500 \mathrm{~g})$ & $135 \mathrm{ml}$ \\
\hline 2. & Fractional model with lipids $(509 \mathrm{~g})$ & $80 \mathrm{ml}$ \\
\hline 3. & Fractional model with cellulose $(850 \mathrm{~g})$ & $117 \mathrm{ml}$ \\
\hline 4. & Fractional model with carbohydrates $(900 \mathrm{~g})$ & $95 \mathrm{ml}$ \\
\hline 5. & Fractional model with fructose $(1164 \mathrm{~g})$ & $87 \mathrm{ml}$ \\
\hline 6. & $\begin{array}{l}\text { Combined fraction }(\text { cellulose }-850 \mathrm{~g}, \text { carbohydrates }-900 \mathrm{~g}, \text { lipids }- \\
500 \mathrm{~g}, \text { fructose } 1164 \mathrm{~g})\end{array}$ \\
\hline
\end{tabular}

After pretreatment, fermentation and ethanol fermentation, the samples have been analyzed by gas chromatography-mass spectrometry (Agilen 7890A15975C) to determine the chemical composition and identify alcohol-containing substances. Passing through the chromatograph, the fractions are separated into components, and the mass spectrometer is responsible for their identification. This type of detection has a high accuracy (95\%), its essence reduces to recording the readings not for the entire volume of the incoming ion current, but for the maximum ions for the supposed molecules, and a graph of the signal (intensity) against time (minutes) is plotted. The measurement error on the gas chromatograph is $\pm 5 \%$. A chromatogram is a graphical representation of the detector signal used to measure the concentration of substances in the eluate, versus the time of the mobile phase. Chromatograms are diagrammed as sequences of Gaussian peaks on a baseline.

In the experiment, 6 samples with different compositions were used. There is also a sample with a combined composition and a natural sample from the landfill. The experiment shows that ethanol can be obtained from any organic fraction, but a comparative analysis of all samples can reveal that the percentage of ethanol in some samples is higher and separation into several separate components is not a prerequisite. The Table 2 shows data on retention times (minutes), peak areas (S) and components, intensity and 
concentration of these substances. These data are the main ones for this method of analysis. The areas of chromatographic peaks (S) are proportional to the volume percentages of the substance in the liquid sample, provided that the catarometer is used to analyze liquid mixtures of substances similar in their chemical structure. Usually, the area of the chromatographic peak is proportional to the concentration (C) of the corresponding component. The area of the chromatographic peak in this case is proportional to the amount of substance that entered the detector at the outlet of the column.

The peak area of the chromatogram is the basis for quantitative calculations of component concentrations. The sum of the peak areas is taken as $100 \%$ and the content of an individual component is calculated by the ratio of the peak areas of the component to the total peak area, thus the percentage $(\mathrm{C} 1, \%)$ of each component in the sample is obtained.

Table2. Combined Sample Components

\begin{tabular}{|l|l|l|l|c|l|}
\hline Peaks\# & \multicolumn{1}{|c|}{ Time $(\mathrm{min})$} & \multicolumn{1}{|c|}{ Area(S) } & \multicolumn{1}{c|}{ Component } & C, \% & \multicolumn{1}{c|}{ C1, \% } \\
\hline 1 & 1.681 & 4237936015 & Ethanol & 94 & 96 \\
\hline 2 & 3.978 & 151571481 & 1-butanol 3-methyl- & 62 & 2.8 \\
\hline 3 & 6.389 & 3217162 & Propanoic acid, 2-methyl & 73 & 0.1 \\
\hline 4 & 9.499 & 28243644 & Oxim-, methoxy-phenyl-_ & 77 & 1 \\
\hline 5 & 17.185 & 2258941 & L- $\alpha$-Terpineol & 71 & 0.1 \\
\hline
\end{tabular}

In accordance with Table 2, a gas chromatography graph with mass spectral detection is presented (Fig.1), which shows the result of recording the dependence of the column outlet intensity on time. The concentration of each peak (\%) is calculated from the peak area. Each peak corresponds to the component and the time at which it was registered, as shown in the table and on the chromatogram, also the peak areas allow you to identify the percentage of each chemical element, this analysis on the chromatograph shows that the experiment really allows you to obtain ethanol and other alcohol-containing substances. The chromatograms of the first five samples were combined into one and only the ethanol concentration was shown. The Table 3 shows the results of gas chromatography analysis of a sample with lipids; this sample contains: ethanol (93.85\%), the retention time required to elute the substance corresponds to the time of the peak maximum in the chromatogram, the peak areas, the intensity or signal of the detector, as well as the data on the percentage of substances in the sample. The percentage of ethanol in the sample with lipids is significantly lower than in the model combined sample, and the content of alcohol-containing substances in this sample is significantly higher than in the previous one.

The main stages of the experiment are thermal treatment, enzymatic hydrolysis and ethanol fermentation, judging by the results, these stages have a favorable effect on the samples and in all samples the predominant substance with a high concentration is ethanol. According to Table 3, a chromatogram is presented (Fig.1), which clearly shows the component intensity and the retention time dependence. The time required for the substance elution corresponds to the time of the peak maximum in the chromatogram. Each peak with a corresponding number reflects a component.

According to the component composition, the lipid sample contains specific aromatic heterocyclic organic compounds, such as pyrazine, monobasic short-chain saturated fatty acids (butyric acid), monohydric phenylethyl alcohol, which is contained in essential oils, which indicates the method reliability and the identification of such components in the sample with lipids.

The results of the analysis of mass spectrometric detection of the sample with cellulose (Table 4). This sample showed the lowest percentage of ethyl alcohol, in contrast to the others, since cellulose contains ligninocelluloses in its composition, which have a dense structure. Lignin is a molecule that consists of phenylpropane units linked in a three-dimensional structure, which is especially difficult to biodegrade, the higher the proportion of lignin, the higher the resistance to chemical and enzymatic degradation.

Figure 1(c) shows a dependence graph of the detector signal (substance intensity) versus time (peak) in a sample with cellulose. Ethanol corresponds to a time and a peak that records the detector response. The sample with carbohydrates (Table 5) after analysis on a gas chromatograph revealed the content of ethanol (96.27\%). The percentage of ethanol in the sample with carbohydrates is close in value to the ethanol in the combined sample, and this sample also has the lowest content of other alcohol-containing components. Thus, it can be assumed that it is carbohydrates that give the greatest yield of ethanol in the combined sample. 


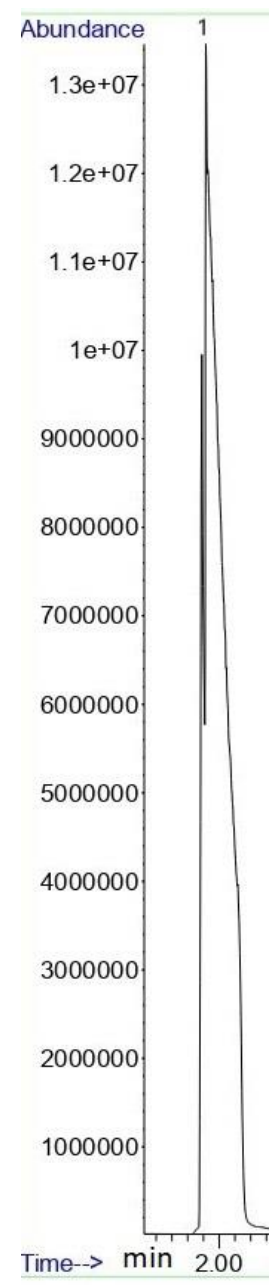

a
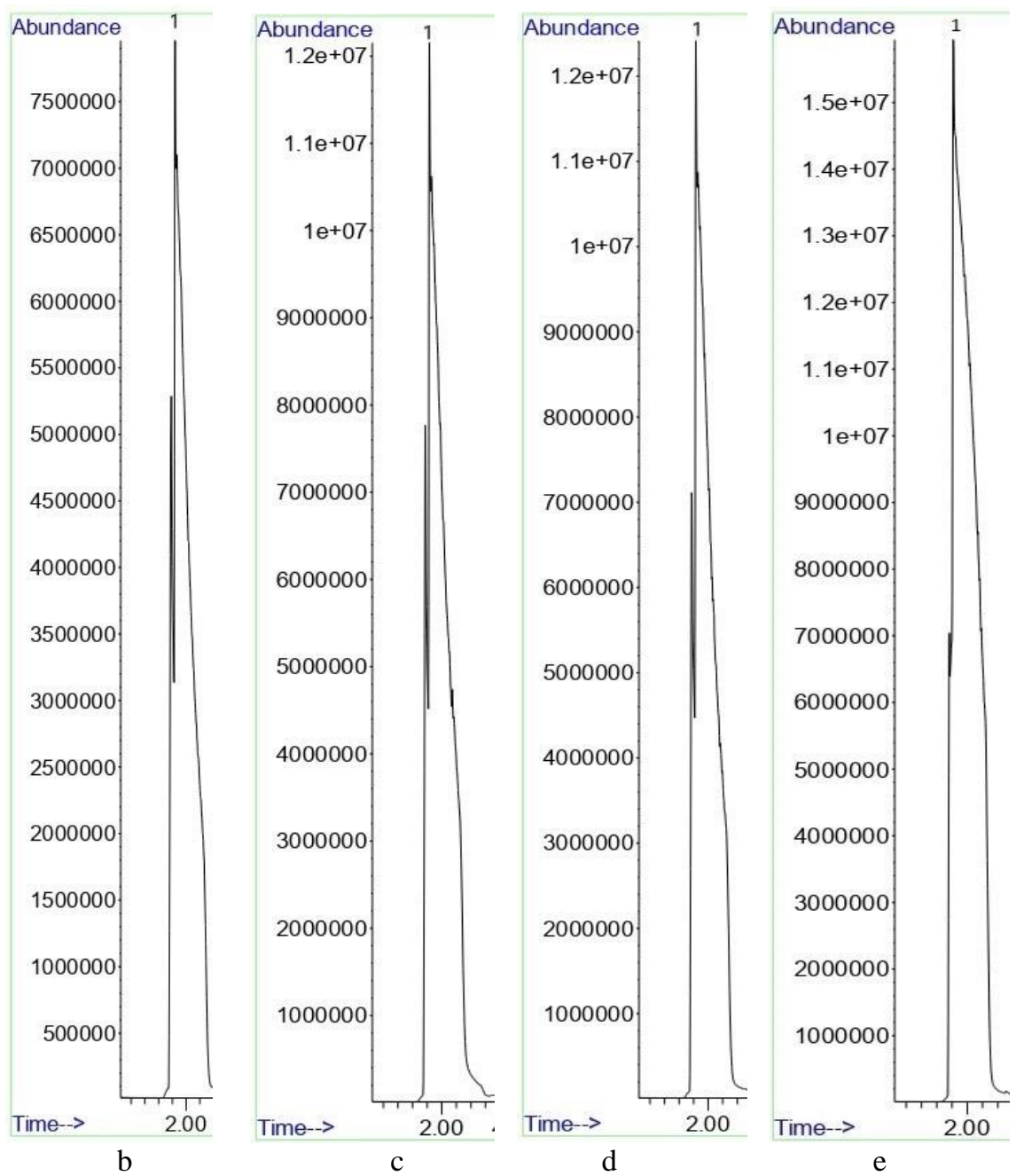

Fig.1. Dependence chromatogram of the components concentration of the combined sample versus time (a-combined sample, b-graph of sample components to lipids ratio, c-dependence chromatogram of the substances concentration and the cellulose sample time, d-graph of concentration of carbohydrate sample components versus time, e-dependence chromatogram of the substances concentration and the sample time the with fructose)

Table 3. Concentration of sample components with lipids

\begin{tabular}{|l|l|l|l|l|l|}
\hline Peaks \# & Time (min) & \multicolumn{1}{|c|}{$\begin{array}{r}\text { Area } \\
(\mathrm{S})\end{array}$} & \multicolumn{1}{|c|}{ Component } & C, \% & C1, \% \\
\hline 1 & 1.733 & 2084267735 & Ethanol & 93 & 93.85 \\
\hline 2 & 3.974 & 66427254 & 1-butanol 3-methyl- & 81 & 2.99 \\
\hline 3 & 6.623 & 3468608 & Propanoic acid, 2-methyl & 83 & 0.16 \\
\hline 4 & 7.407 & 4610257 & Butanoic acid & 77 & 0.21 \\
\hline 5 & 8.522 & 10123063 & Butyric acid, 3-methyl & 63 & 0.46 \\
\hline 6 & 9.576 & 31078988 & Oxime-, methoxy-phenyl- & 85 & 1.40 \\
\hline 7 & 15.176 & 9813476 & Pyrazine, tetramethyl- & 80 & 0.44 \\
\hline 8 & 16.477 & 9109129 & Phenylethyl alcohol & 74 & 0.41 \\
\hline 9 & 27.674 & 1155125 & Triethyl citrate & 75 & 0.05 \\
\hline 10 & 33.817 & 909606 & Phthalic acid, butyl hex-3-yl ether & 77 & 0.04 \\
\hline
\end{tabular}


Table 4. Concentration of sample components with cellulose

\begin{tabular}{|l|l|l|l|c|c|}
\hline \multicolumn{1}{|c|}{ Peak } & \multicolumn{1}{c|}{ Time (min) } & \multicolumn{1}{|c|}{ Area (S) } & \multicolumn{1}{c|}{ Component } & C, \% & C1, \% \\
\hline 1 & 1.718 & 2571350344 & Ethanol & 92 & 90.84 \\
\hline 2 & 3.986 & 201445006 & 1-butanol 3-methyl & 81 & 7.12 \\
\hline 3 & 9.513 & 37545433 & Oxime, methoxyphenyl & 79 & 1.33 \\
\hline 4 & 33.818 & 20161521 & Dibutyl phthalate & 96 & 0.71 \\
\hline
\end{tabular}

Table 5. Concentration of sample components with carbohydrates

\begin{tabular}{|l|l|l|l|c|c|}
\hline Peak & \multicolumn{1}{|c|}{ Time $(\mathrm{min})$} & \multicolumn{1}{|c|}{ Area $(\mathrm{S})$} & \multicolumn{1}{c|}{ Component } & C, \% & C1, \% \\
\hline 1 & 1.715 & 3312233598 & Ethanol & 93 & 96.28 \\
\hline 2 & 4.215 & 88291610 & 1-butanol 3-methyl & 69 & 2.57 \\
\hline 3 & 9.497 & 39044278 & Oxime methoxyphenyl & 79 & 1.15 \\
\hline
\end{tabular}

The chromatogram of the carbohydrate model sample is shown in Figure 1 (d), component corresponds to a peak number and retention time. Each peak of the chromatogram was indicated by a number, using the table. The model fraction with fructose (Table 6) after analysis on a gas chromatograph revealed the content of such chemicals as: ethanol (94.2\%) and others. The sample with fructose has a few percent lower concentration of ethanol than the sample with lipids and carbohydrates, but higher than the cellulose sample.

Table 6. Concentration of sample components with fructose

\begin{tabular}{|l|l|l|l|c|c|}
\hline Peak & \multicolumn{1}{|c|}{ Time $(\mathrm{min})$} & \multicolumn{1}{|c|}{ Area $(\mathrm{S})$} & \multicolumn{1}{c|}{ Component } & C, \% & C1, \% \\
\hline 1 & 1.651 & 6352024114 & Ethanol & 92 & 94.2 \\
\hline 2 & 3.661 & 27886911 & Vinegar acid & 68 & 0.4 \\
\hline 3 & 3.986 & 329117680 & 1-butanol 3-methyl & 85 & 4.9 \\
\hline 4 & 9.334 & 20281542 & Oxime methoxyphenyl & 79 & 0.3 \\
\hline 5 & 33.819 & 15463353 & Dibutyl phthalate & 93 & 0.2 \\
\hline
\end{tabular}

In accordance with Table 6, a gas chromatography graph (Fig.1) with mass spectral detection is presented, which shows the result of recording the dependence of the column outlet intensity on time. A natural sample from the Almaty landfill after a qualitative experiment with fermentation showed the highest ethanol content $-97.5 \%$ in contrast to the rest of the samples, the Table 7 shows the peak recording time, the area and intensity of each component, as well as the concentration of these substances. The chromatogram of the substances intensity, the peak area and the retention time of the sample with the organic fraction of the municipal solid waste of the landfill in Almaty is shown in Figure 2. The expanded chromatogram is shown in this figure.

Table 7. Concentration of natural sample components from the landfill of Tartyp JSC, Almaty:

\begin{tabular}{|l|l|l|l|c|c|}
\hline Peak & \multicolumn{1}{|c|}{ Time (min) } & \multicolumn{1}{|c|}{ Area (S) } & \multicolumn{1}{c|}{ Component } & C, \% & C1, \% \\
\hline 1 & 1.731 & 2339904556 & Ethanol & 91 & 97.5 \\
\hline 2 & 9.559 & 44417720 & Oxim, methoxyphenyl & 80 & 0.2 \\
\hline 3 & 14.317 & 5705926 & $\begin{array}{l}\text { Ethyl 2- (5-methyl-5-vinyltetrahydrofuran- } \\
\text { 2-yl), propan-2-yl carbonate }\end{array}$ & 86 & 0.2 \\
\hline 4 & 15.18 & 7123396 & Pyrazine, tetramethyl & 81 & 0.3 \\
\hline 5 & 16.779 & 2328081 & $\begin{array}{l}\text { 2H-pyran-3-ol, 6-ethenyltetrahydro-2,2,6- } \\
\text { trimethyl }\end{array}$ & 63 & 0.1 \\
\hline 6 & 17.185 & 1557327 & $\alpha$-Terpineol & 67 & 0.1 \\
\hline
\end{tabular}

A high concentration of ethanol was detected in a natural sample from a solid waste landfill. Thus, it can be assumed that even without separation and fractionation of elements that are usually present in the organic fraction of solid household waste during sample processing and performing enzymatic hydrolysis 
and ethanol fermentation, ethanol and other alcohol-containing substances can be obtained and used as an alternative energy source in the future. This experiment showed that some elements, such as cellulose, inhibit the formation of ethanol, due to the presence of lignin in the composition. The lipid test revealed a large number of aromatic substances and proved its lipid component. The sample with carbohydrates also has a higher concentration, which indicates that carbohydrates give a greater effect of alcohol formation in comparison with other samples.

The effectiveness of this method lies in the fact that all the samples that were analyzed have a very high potential for producing ethanol. Solving the problem of the organic fraction of solid household waste, a large range of environmental, economic and energy problems is solved. The ecological situation near the municipal solid waste landfill in Almaty is well known and requires measures to prevent the formation of methane and carbon monoxide, which poisons the soil and water in the nearest settlements. The country's energy reserves require the search for an alternative, so ethanol or in other words, technical alcohol obtained from waste can serve as fuel for cars that collect waste throughout the city.

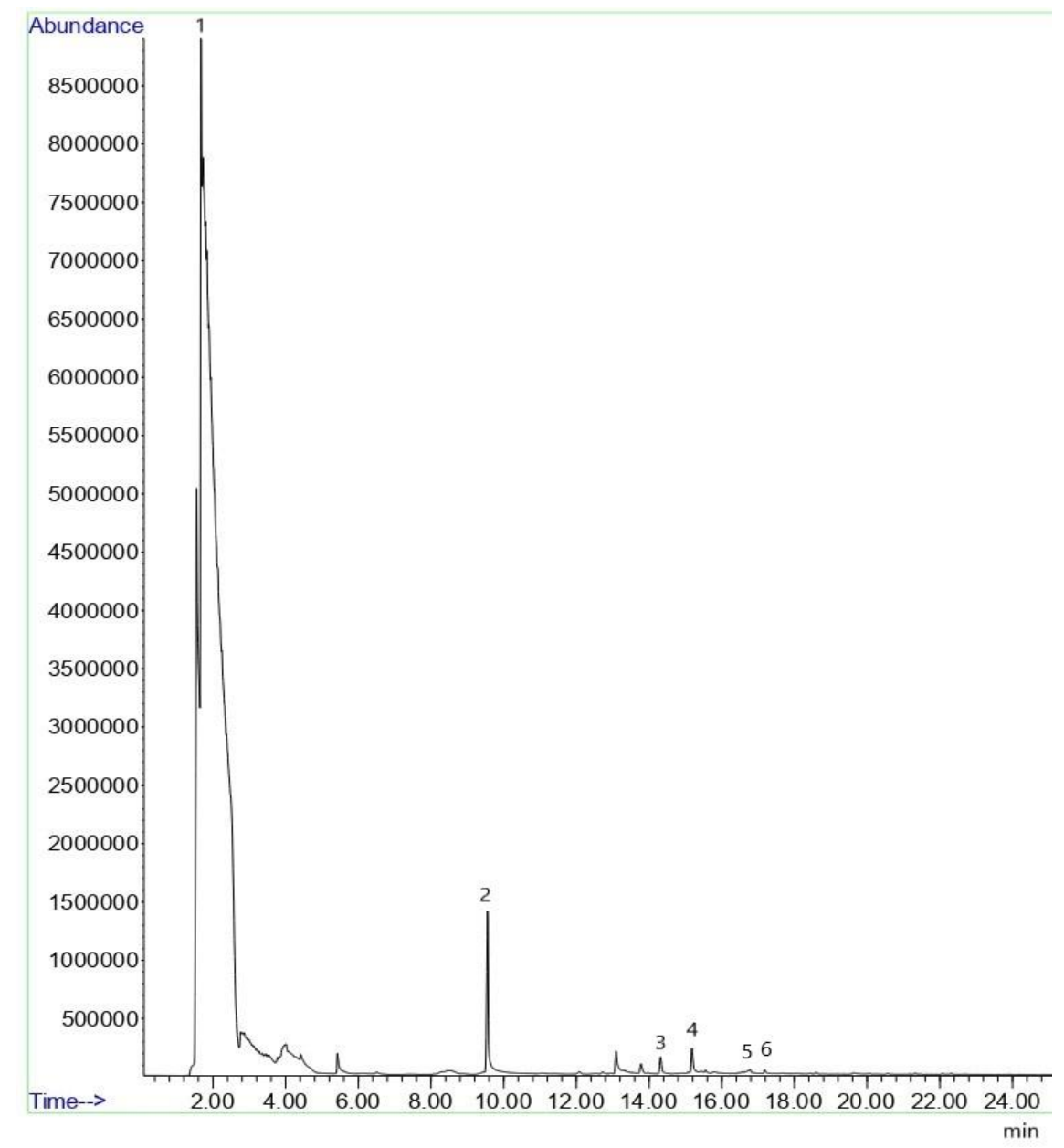

Fig.2. Graph of concentration of natural sample components from the landfill of Tartyp JSC in Almaty

Preliminary heat treatment was used in this experiment to resolve complex molecules and prepare raw materials for the formation of ethanol. Also, when working with waste, heat treatment is a very necessary stage, since the raw materials are decontaminated, which contributes to an environmentally friendly approach. Processing takes place at a temperature of $120^{\circ} \mathrm{C}$. Enzymatic hydrolysis of samples is carried out for deep destruction with the formation of soluble sugars under the action of poly-enzyme systems. Amylosubtilin, glucavamorin, and cellulose were used as such systems. This stage prepares samples for ethanol fermentation. 


\section{Conclusions}

Thus, ethyl alcohol is present in the highest concentration in all analyzed samples, which indicates that pretreatment, fermentation, and ethanol fermentation with alcoholic yeast had a positive effect. The ethanol concentration in a natural sample from the Almaty landfill has the highest rate of $97.5 \%$, in contrast to the others, which indicates that this sample has the maximum potential for its production. Fractional samples with different homogeneous and heterogeneous composition and natural sample from the landfill have been selected to assess the difference in the fermentation degree and alcohol concentration.

According to the results, it can be inferred that the combination of components and a heterogeneous composition, as in a natural sample of municipal solid waste, can contribute to an increase in the concentration of alcohol and other alcohol-containing substances. Consequently, the mixed raw material contains more components and enzyme induction improves their bioavailability and prepares them for ethanol fermentation with alcoholic yeast, and pre-treatment promotes the decomposition of lignin and lignincellulose, which are present in the composition of various components of municipal solid waste.

Results from the presented experimental work indicated that waste collected in mixed form have a remarkable potential of use without the need of separation according to carbohydrate fractions to produce ethanol. Biofuel energy in our country is at the very beginning of its development, so the scientific novelty is that this technique is not used to solve environmental and energy problems, namely in relation to waste, when both the situation and the problem with them are significant.

Currently, renewable energy sources represent only about $2.3 \%$ percent in the energy balance of Kazakhstan. In fact, about 9/10 of all electricity is generated by burning hydrocarbons. The results obtained reflect the prospect of using ethanol from waste as renewable energy sources. The advantage of this method is environmental friendliness. Supporting global efforts to reduce greenhouse gas emissions and improve the climate, it is necessary to develop alternative energy by producing ethanol from the organic fraction of municipal solid waste.

\section{REFERENCES}

1 Kim S., Dale B.E. Global potential bioethanol production from wasted crops andcrop residues. Biomass Bioenergy. 2004, Vol. 26 (4), pp. 361-375.

2 Reijnders L. Ethanol production from crop residues and soil organic carbon. 2008, 658 p.

3 Sarkar, N., Ghosh, S.K., Bannerjee, S., Aikat, K. Bioethanol production from agricultural wastes: an overview. Renewable Energy/2021, No. 37 (1), pp. 19-27.

$4 \mathrm{Ma}$, Y., Cai, W., Liu, Y., 2017a. An integrated engineering system for maximizing bioenergy production from food waste. Appl. Energy. 2017, 206 (C), pp. 83-89.

5 Yan, S., Li, J., Chen, X., Wu, J., Wang, P., Ye, J., Yao, J. Enzymatical hydrolysis of food waste and ethanol production from the hydrolysate. Renewable Energy. 2001, No. 36 (4), pp. 1259 - 1265.

6 Nozhevnikova A.N. Biotechnology and microbiology of anaerobic digestion of organic household waste. 2016, $320 \mathrm{p}$.

7 Alavi Moghadam M.R., Mokhtarani N., Mokhtarani B. Municipal solid waste management in Rasht City. Iran. Waste Manage. 29 (1), 2009, 485-489 p.

8 Sharholy M., Ahmad K., Vaishya R., Gupta R. Municipal solid waste characteristics and management in Allahabad, India. Waste Manage. 2007, No. 27 (4), pp. 490-496.

9 Talyan V., Dahiy R., Sreekrishnan T. State of municipal solid waste management in Delhi, the capital of India. Waste Manage. 2008, No. 28 (7), pp. 1276 - 1287.

10 Yousuf T.B., Rahman M., Monitoring quantity and characteristics of municipal solid waste in Dhaka City. Environ. Monit. Assess. 2007, No. 135 (1), pp. 3-11.

11 Taherzadeh M.J., Karimi K., Pretreatment of lignocellulosic wastes to improve ethanol and biogas production: a review. Int. J. Mol. Sci. 9, 2008, pp. 1621 - 1651.

12 Komilov O.S., Sharipov M.Z., Tilloev L.I., Majidov J.A., Autonomous biogas installation with solar heating system. Eurasian Physical Technical Journal, Vol.15, No. 1(29), 2018, 82-85 p.

13 Mahmoodia P., Karimi K., Taherzadeh M.J. Hydrothermal processing as pretreatment for efficient production of ethanol and biogas from municipal solid waste. Bioresource Technology. 2018, Vol. 261, pp. 166-175. 